\title{
The pirate from Koenigsberg: why closed source software is not worth of copyright protection
}

\section{Maria Chiara Pievatolo}

<pievatoloddsp. unipi.it>

Copyright (C) 2007 Maria Chiara Pievatolo

This work is licensed under a Creative Commons Attribution-Noncommercial-Share Alike 3.0 License.

\begin{abstract}
According to Kant, property applies only to touchable things, among which he includes the works of art. For the very principle of private property, a legitimate purchaser has the right to replicate and to share them without restrictions.
\end{abstract}

Kant recognizes copyright only on written texts, by conceiving them as speeches that exclusively authorized spokespersons - the publishers - may convey to the public in the name of their authors. The rights of the authorized publishers, however, are justified only if they help the public to get the texts.

In a Kantian environment, open source software would be worth of copyright protection, because it can be conceived as a speech meant to human beings. On the contrary, Kant would treat closed source programs as works of art, without according them copyright protection, because, as none is allowed to read and to understand them, they cannot be conceived as a speeches meant to the public. Closed source programs are like sealed books that no one is allowed to read: why do we keep on taking for granted that they are worth of copyright protection?

\section{Table of Contents}

$\underline{\text { About the author }}$

$\underline{\text { Introduction }}$

1. Kant's theory of copyright as ius personale

2. Would a Kantian copyright be a viable solution today?

3. Applying Kant's copyright to software

$\underline{\text { References }}$

\section{About the author}

Maria Chiara Pievatolo (http://www.sp.unipi.it/hp/pievatolo) is an associate professor of political philosophy in the Political Science faculty at the university of Pisa, Italy.

\section{Introduction}

In 1785 Immanuel Kant wrote a short essay, Von der Unrechtmäßigkeit des Büchernachdrucks, which is usually translated as Of the injustice of counterfeiting books. As most scholars, in the field of humanities, take intellectual property for granted, the mistaken representation of Kant like an intellectual property forerunner is still a commonplace. ${ }_{-}^{1}$ However, if we read Kant's essay in a more accurate way, on the background of the Enlightenment debate on copyright, we can reach some surprising conclusions: Kant's ideas on copyright could help us in advocating the public domain and the users' rights and involve some interesting consequences, especially if we succeed in extending them to the realm of software. 
In Kant's age, the word Nachdruck, $\underset{-}{2}$ now translated as "counterfeiting" o "piracy", had the proper and less criminal meaning of "reprint". The United Kingdom had passed in 1710 the first European copyright bill, the Statute of Anne, which received a definitive interpretation only in 1774, in the well-known judgment on Donaldson vs. Beckett 3 s settled by the House of Lords. In Germany, on the contrary, the continuation of the early modern privilege ${ }_{-}^{4}$ regime and the multitude of states and jurisdictions facilitated the practice of the Nachdruck by further printers after the first publication. And it was highly controversial whether such a practice were rightful or should be considered piracy.

The debate on the Nachdruck was not restricted to publishers and lawyers: as the Enlightenment intellectuals were aware of the political importance of disseminating knowledge, major thinkers like Lessing, Kant and Fichte took part to it. Kant's ideas, in particular, are worth of a closer scrutiny because he, while arguing against the Nachdruck, rejects the concept of intellectual property, and recognizes some rights to the public in general. Besides, if we extend Kant's copyright notion to software, we can derive the intriguing consequence that only free software, properly, deserves copyright protection. To reach such a conclusion, however, we need an accurate understanding of Kant's arguments, which can help us to reformulate a more balanced concept of copyright.

\section{Kant's theory of copyright as ius personale}

At the conclusion of his essay Von der Unrechtmäßigkeit des Büchernachdrucks, Kant makes a seemingly inconspicuous remark:

If the idea of the publication of books in general, built upon here, were well-prepared, and (as I flatter myself it is possible) elaborated with the elegance requisite to the Roman juridical learning: then the complaint against the counterfeiter might well be brought before a court, without first needing to ask on that account for a new law. $\frac{5}{-}$

At the time, there were no copyright laws in German states: Kant, here, is asserting that they would not be even required, if his ideas were applied. His remark on "the elegance requisite to the Roman juridical learning" is hardly casual.

According to Roman Law, property is only possible on material, touchable things - the so-called res quae tangi possunt. In the "battle of the booksellers" that raged in England for more than half a century, Roman Law tradition was an important landmark. While the English booksellers argued that copyright was a common law property, therefore unlimited and perpetual, the Scottish booksellers recognized only the Statute of Anne terms, $\underset{-}{6}$ on the basis of the Scottish Roman Law tradition that denied the very possibility of property on immaterial objects.

On the basis of the same Roman Law tradition, the law faculty of Leipzig stated in 1665 that the property of the publisher on a purchased manuscript is only a ius reale on it as a material thing. Later, in 1722. the law faculty of Jena declared that the paternity of a text gave the author or his delegate neither a property right on its printed copies nor the right to forbid its Nachdruck. ${ }^{7}$ At the end of his essay on copyright, Kant, by evoking Roman Law as a model, is clearly showing his endorsement to its pattern. It is worth noticing that Richard Stallman repeats an ancient Roman Law thesis, when criticizing intellectual property as based on an overstretched analogy with material objects.

When I cook spaghetti, I do object if someone else eats it, because then I cannot eat it. His action hurts me exactly as much as it benefits him; only one of us can eat the spaghetti, so the question is, which? The smallest distinction between us is enough to tip the ethical balance.

But whether you run or change a program I wrote affects you directly and me only indirectly. Whether you give a copy to your friend affects you and your friend much more than it affects 
me. I shouldn't have the power to tell you not to do these things. No one should. 8

Accordingly, Kant distinguishes between the book as a touchable object and the thoughts it conveys. The book as a material object becomes a property of whoever buys it. For the very principle of private property, it is not fair to restrain the ways in which its legitimate purchaser may use it. Therefore, if we intend a book as a material object, we must admit that its buyer may copy it. On the other hand, the thoughts that are published in a book remain a "property" of their author, regardless of their reproduction, because they are not material resources: you can continue to conceive your ideas even if they are thought by everyone and their written expressions are indefinitely reproduced. $\stackrel{9}{-}$

Property makes sense only in the case of material objects, because they cannot be owned and used by everyone at the same time. On the contrary, ideas can be thought by everyone, without depriving their authors. Even the question of the actual paternity of an idea does not properly concern property, but historical truth. Properly speaking, the plagiarist pretending another person's ideas are his own, is not a thief, but a liar.

Knowledge is not a material object exposed to a competitive use; for this reason, it is senseless to forbid the reproduction of ideas. On the other hand, it is equally senseless to forbid the reproduction of any touchable object, if it has been purchased in a legal transaction and the purchasers copy it by their own means. Therefore, if we conceive intellectual property as a right on material objects (jus reale or real right), any reservation of copyright is untenable.

Kant tries to switch his perspective from real to personal rights, in the traditional meaning of rights entitling someone to obtain acts from other persons. 10 As personal rights concern relations among free beings, they can arise only from expressed agreements.

When I speak to a public, I engage a relationship with it. In this perspective, a book is not only a physical object, but it is also the medium through which authors can transmit their speeches to a wider public. In the age of printing, such a medium was not provided by the authors, but by other persons, the publishers. By giving them the means to reach a wider public, publishers, as it were, speak in the name of authors, as their spokespersons. But someone may speak in the name of another person - and engage the latter in a relationship with the public - only if he has the latter's authorization. The authorized publisher of a book ought to be only one, Kant adds, because a reproduction by another publisher would be useless and would spoil the business of both. 11

The mandate of the author to the publisher is only a personal relationship that does not imply the acquisition of proprietary rights on the text. The goal of such a personal relationship is conveying a speech to the public in its indefinite wideness. The public, on the other hand, has a right to the speech regardless of the publisher, whose privileges are justified only as long as he act as a $\mathrm{n}$ actual spokesperson. Consequently, the publisher may neither refuse to publish - or to hand over to another publisher, if he does not want to do it himself - a text of a dead author, nor release mutilated or spurious works, nor print only a limited impression that does not meet the demand. $\underline{12}$

Kant does not recognize works of art as speeches. He calls works of art Werke or opera, i.e. things that are produced, while indicating books as Handlungen or operae, i.e. actions. As the works of art are simply physical objects, we can derive from Kant's assumption that every legitimate purchaser may reproduce them and pass the copies to others. $\underline{13}$

Kant backs the restriction of the freedom to reproduce a text only in connection with the author as a living person and with the latter's action towards the public. When the author disappears, the public interest for a free circulation of information prevails. And every time a creative work is treated as a proprietary thing, Kant see no legal hindrances to the freedom of its legitimate owner to reproduce it. 
Kant would endorse as legitimate even the so-called piracy, that is to say the reproduction of music, songs, images and so on to gift or to sell them to others. Furthermore, he would justify even texts reproduction for a personal use: the problem with unauthorized printing is only the circumstance that the printer speaks to the public without a mandate from the author. But if you reproduce a text only to read or to study it by yourself, you do not speak to a public in the name of its author.

Kant's position does not rely on pure reason only, but it involves a perhaps intentional empirical contamination. In the essay of 1785 , the ground for the the exclusive nature of the mandate to a publisher is only the interest of the latter to avoid competition. 14 In the later, and more theoretical, Metaphysik der Sitten, Kant does not mention the question at all. 15

In Kant's world the press used to be the medium that provided for the widest distribution of ideas. Printing required both specific tools and skills, and specialized and centralized organizations. And as long as the publishers of printed texts provided the only medium to convey speeches to a wide public, Kant could not avoid to bow to their interest.

Anyway, the primacy of the publishers' interest was not based on reason, but only on technology. If there were a medium directly connecting authors and the public, without relying on publishers, respecting their interests would become senseless. Such a medium, today, is the Internet. The interest of science to the public use of reason overlapped with the interests of publishers only provisionally and by chance, because of a past state of art in media technology.

\section{Would a Kantian copyright be a viable solution today?}

We can sum up Kant's theory of copyright in the following points:

1. There is not such a thing as "intellectual property": property applies only to material objects, while ideas can be indefinitely shared without impoverishing anyone.

2. Private property on material things ought to be taken seriously: you have the right to replicate and to share all what you have legitimately purchased. After all, it is yours.

3. A work of art is only a material object. If it is sold as a commodity and you buy it, you have the right to reproduce and to share it as you please. After all, it is yours.

4. Everyone has the right to decide who should speak to the public in his or her name, by giving his or her spokesperson a mandate.

5. A written text is like a speech; the publisher who prints it is a spokesperson of the author; therefore, the former should have the latter's mandate to be a legitimate publisher.

6. The public has the right to get the speeches the authors want to convey: the rights of the publishers are legitimate when they both have the authors' mandate and do their work of spokespersons in a proper way, by facilitating the dissemination of the speeches and not by hindering it.

7. The right of the public to the speech prevails on the right of the publisher, if the latter hinders the spreading of its text.

Reproduction in itself has nothing to do with piracy. We have piracy only when the copies of a texts are distributed to the public against the expressed will of their authors. When the authors cannot express their will any longer, the right of the public must prevail on the right of the publisher if the latter does not help the public to gain access to the texts. Every product that cannot be conceived as the speech of a person should be treated as a commodity and should be subjected to the rules of private property in its Roman Law meaning.

Such a formulation, today, would protect the right of the authors to decide whether and where to publish their texts. Furthermore, it would protect the publishers' interest when - and only when - their intermediation activity is still useful to reach a wider public, and, above all, it would avoid the people copying or letting others reproduce copyrighted stuff only for personal use were treated like criminals. In addition, it would 
promote a truly free market, without monopolies, on all what can be conceived as a mere physical product.

\section{Applying Kant's copyright to software}

In our days, copyright has been extended from the written texts of Kant's age to many other products, including software. If we embrace Kant's ideas, however, software can be copyright protected if and only if we can conceive it as speech addressed to human beings. 16

A piece of software is a collection of instructions, written in a programming language with its own syntax. Its only difference with ordinary human speech is that the instructions it contains are not written to speak to a public, but to be executed by a computer. People can use it like a part of a mechanism, but it is not meant for them.

Closed source or proprietary software is distributed as compiled binary. People are not even allowed to reverse engineer it, i.e. to translate it in a speech meant for them: a programmer writing closed source software is not addressing people, but only computers. We are compelled not to treat it as speech, but only as a part of a mechanism, or a part of a work of art. Therefore, it should be viewed as a product, subjected to the private property rules. If you buy Windows Vista, you ought to be entitled to copy it and to share its copies in the ways you prefer, like you have the right to do on other commodities.

I might be objected that a compiled binary is, as it were, an artificial speech. Its source is a speech written by a human being: the binary is like a translation to make it more easily understandable by a computer. As its source is a speech written by a human being, so should be its binary translation. It is also possible to discover its source, if you are skilled in reverse engineering.

According to Kant, however, a translation should be considered as an original speech, whose copyright belongs only to the translator. The latter does not need to ask the translated text author his permission, because its translation depends only on his skill: therefore, it can be considered as a new speech. 17 For the same reason, if a reverse engineer reconstructs, from the binary, the source, by means of his deduction skills, the copyright of the resulting program should belong to him.

But what about the binary? Why could not be considered as an artificial speech, addressed to an artificial intelligence?

First of all, we are not dealing with ontology, but with law. Our question is not whether an artificial speech can be considered as a speech in general, but whether we, human beings, can recognize it as such and what attitude we should have to it. Alan Turing himself, when researching the possibility of an artificial intelligence, contrived a test, the Imitation Game, that was based on the model of human intelligence. 18 We can be sure that a computer is an artificial intelligence when we cannot distinguish its answers from the answers of a human being. This artificial intelligence is an intelligence only for us, from our point of view, when it succeeds in communicating us a speech meant to us. What further pattern of intelligence could we know, beyond what we can recognize? Similarly, how could we assert that an object is a speech, if we must not even try to understand its meaning, or, better, we are not allowed to understand it?

When we deal with open source software, we are in a different position: free software is written in a language meant explicitly not only for computers, but also for human beings. An open source programmer is addressing not only computers, but fellow programmers and users as well.

If free software can be easily conceived as a speech meant to human beings, therefore, in a Kantian environment, it deserves copyright protection, with the same qualifications adopted for literary and scientific texts. The GPL license, which protects both the authors' right to decide how to publish and distribute their works and the right of the public to access them, would be endorsed by Kant, along with more restrictive 
licenses - provided they are applied to open source software.

In a Kantian environment, such a qualified copyright protection would encourage programmers to share their works and to improve, by sharing it, the code they give to the public and would discourage the production of closed source software. A closed source program is like a sealed book that no one is allowed to read: why do we keep on taking for granted that it is worth of copyright protection?

\section{Notes}

[1] See for instance Hurt and Schuchman. 1966, 423, and Lacey, 1989, 1541-42.

[2] Check its definition in J. Grimm and W. Grimm. 1854-1960, at http://germazope.uni-trier.de/Projects/WBB/woerterbuecher/dwb/wbgui?lemid=GN00274

[3] See Donaldson v. Beckett. Proceedings in the Lords on the Question of Literary Property, February 4 through February 22, 1774, in Tallmo at http://www.copyrighthistory.com/donaldson.html

[4] The major difference between copyright and privilege is that the former is a universal right, while the latter depends on a grant from the Crown. The former, in other words, is due to every author, while the latter derives from a decision of the political power.

[5] Kant, 1785, A 87.

[6] The Statute of Anne created a 21 year term for all works already in print at the time of its enactment and a 14 year term for all works published subsequently. See it in Tallmo at http://www.copyrighthistory.com/anne.html

[7] See Maccarthy, 1989, 536-537.

[8] See Stallman, 2002.

[9] Kant, 1785, A 79. Such an idea is similar to what Reimarus asserted against intellectual property in Reimarus, 1791. He remarked that the paternity of an idea is not affected by its printed reproduction, because the latter can not take away from its author the historical fact that the idea itself had been conceived by him.

[10] Kant, 1797: Rechtslehre §18, A 271: "the possession of the active free-will of another person, as the power to determine it by my will to a certain action".

[11] Kant, 1785, A 80-92.

[12] Kant, 1785, A 83-84

[13] Kant, 1785, A 85-86. M. Rose (Rose, 1993, 1-30) asserts that in the early Modernity text was conceived not as a thing, but as an action. At the times of Tudor, Stationers Company copyright was only an exclusive right to print a particular text, granted by the Crown. When Kant treats texts as actions, he adopts an early modern perspective, but with a remarkable difference: the right to print is not granted by the Crown, but by the author himself.

[14] Kant, 1785, A 81 
[16] According to David S. Touretzky (Touretzky, 2000) we cannot distinguish between source and object code on the basis of their human readableness. "Even binary machine code is perfectly readable by humans. It was, after all, designed by humans."

[17] Kant, 1785, A 86-87.

[18] Turing, 1950.

\section{References}

Immanuel Kant, 1784, Von der Unrechtmäßigkeit des Büchernachdrucks, at http://www.ikp.uni-bonn.de/kant/aa08/077.html (on-line version of the Akademie Textausgabe). English translation at http://www.hkbu.edu.hk/ ppp/fne/essay3.html

Johann Albert Heinrich Reimarus, 1791, "Der Bücherverlag in Betrachtung der Schriftsteller, der Buchhändler und des Publikums abermals erwogen" Deutsches Magazin. 1. Bd. pp. 383-414, now at http://archiviomarini.sp.unipi.it/28/

Immanuel Kant, 1797, Die Metaphysik der Sitten at http://www.ikp.uni-bonn.de/Kant/aa06/203.html (on-line version of the Akademie Textausgabe); English translations at http://www.hkbu.edu.hk/ ppp/K1texts.html\#I

Jacob Grimm, 1854-1960, Deutsches Wörterbuch, Lepzig: S. Hirzel, now at http://germa83.uni-trier.de/DWB/welcome.htm

Alan Turing, 1950, "Computing machinery and intelligence”, Mind. LIX, 236, October, pp. 433-460, now at http://www.abelard.org/turpap/turpap.htm

Robert M. Hurt and and Robert M. Schuchman, 1966, "The Economic Rationale of Copyright". The American Economic Review. Vol. 56, No. 1/2. (March), now at http://links.jstor.org/sici?sici=0002-8282\%28196603\%2956\%3A1\%2F2\%3C421\%3ATEROC\%3E2.0.CO\%3B2-\%23

Linda J. Lacey, 1989, “Of Bread and Roses and Copyrights”, Duke Law Journal, 1989, 6. pp. 1532—1596, now at http://links.jstor.org/sici?sici=0012-7086\%28198912\%292\%3A1989\%3A6\%3C1532\%3AOBARAC\%3E2.0.CO\%3B2

John A. Mccarthy, 1989, "Literatur als Eigentum: Urheberrechtliche Aspekte der Buchhandelsrevolution", $M L N$. vol. 104, no. 3, pp. 531-547, now at http://links.jstor.org/sici?sici=0026-7910\%28198904\%29104\%3A3\%3C531\%3ALAEUAD\%3E2.0.CO\%3B2-4

Mark Rose, 1993, Authors and Owners, The Invention of Copyright, Cambridge Mass.: Harvard U.P.

William M. Gordon, 1995, "Roman Law in Scotland", in R. Evans-Jones, The Civil Law Tradition in Scotland. The Stair Society: Edinburgh, supplementary series, vol. 2, pp. 13-40, now at http://iuscivile.com/materials/reprints/gordon-1.htm

Richard M. Stallman, 2002, "Why Software Should Not Have Owners" at http://www.gnu.org/philosophy/why-free.html, now also in R.M. Stallman, Free Software, Free Society: Selected Essays of Richard M. Stallman. , Boston: Free Software Foundation. 
David S. Touretzky, 2000. "Source vs. Object Code: A False Dichotomy", at

http://www.cs.cmu.edu/ dst/DeCSS/object-code.txt, accessed on 24 February 2007.

Karl-Erik Tallmo, "The History of Copyright: A Critical Overview With Source Texts in Five Languages" at http://www.copyrighthistory.com/index.html, accessed on 24 February 2007. 